\title{
Understanding variation in rates of referral among general practitioners: are inappropriate referrals important and would guidelines help to reduce rates?
}

\author{
Arnold Fertig, Martin Roland, Hugh King, Tim Moore
}

\begin{abstract}
Objectives-To determine the extent to which variation in rates of referral among general practitioners may be explained by inappropriate referrals and to estimate the effect of implementing referral guidelines.

Setting-Practices within Cambridge Health Authority and Addenbrooke's Hospital, Cambridge.

Main outcomemeasures-Data on practice referral rates from hospital computers, inappropriate referrals as judged by hospital consultants, and inappropriate referrals as judged against referral guidelines which had been developed locally between general practitioners and specialists. Effect of referral guidelines on referral patterns as judged by general practitioners using the guidelines in clinical practice.
\end{abstract}

Results-There was $2 \cdot 5$-fold variation in referral rates among general practices. According to the specialists, $9 \cdot 6 \%(95 \%$ confidence interval $6.4 \%$ to $12.9 \%$ ) of referrals by general practitioners and $8.9 \%$ $(2 \cdot 6 \%$ to $15 \cdot 2 \%)$ of referrals from other specialists were judged possibly or definitely inappropriate. Against locally determined referral guidelines $15.9 \%$ of referrals by general practitioners were judged possibly inappropriate $(11 \cdot 8 \%$ to $20 \cdot 0 \%)$. Elimination of all possibly inappropriate referrals could reduce variation in practice referral rates only from $2 \cdot 5$-fold to $2 \cdot 1$-fold. An estimate of the effect of using referral guidelines for 60 common conditions in routine general practice suggested that application of guidelines would have been unlikely to reduce rates of referral in hospital $(95 \%$ confidence interval $-4.5 \%$ to $8.6 \%$ of consultations resulting in referral).

Conclusion-The variation in referral rates among general practitioners in Cambridge could not be explained by inappropriate referrals. Application of referral guidelines would be unlikely to reduce the number of patients referred to hospital.

\section{Introduction}

There is wide and unexplained variation in the rates at which general practitioners refer patients to hospital. ${ }^{22}$ The variation has itself been taken to indicate that resources are being used inefficiently and that patients may be referred to hospital unnecessarily. If variation in rates was due in part to general practitioners referring patients unnecessarily then it should be possible to identify a substantial number of unnecessary referrals in any sample of referrals drawn from an area where there is appreciable variation in rates among general practitioners. Our main aim was to test this hypothesis.

In assessing the appropriateness of referrals it is important to appreciate that the perspectives of the specialist, the general practitioner, and the patient on appropriateness are probably different. ${ }^{3-5}$ From the medical perspective assessment of the appropriateness of referrals should entail at least the views of specialists and general practitioners, and several joint groups have been established to develop guidelines for referral. ${ }^{67}$
Such guidelines, however, may still fail to include the patient's perspective as patients' expectations of referral may differ from, objectives of doctors. These issues are discussed in more detail in two recent publications. ${ }^{58}$

In this study we have been able to take advantage of a set of referral guidelines which had been developed locally between general practitioners and specialists in the study district. We used these guidelines as a measure of the appropriateness of referrals to assess the maximum contribution which referrals rated by doctors as possibly unnecessary could have made to variation in referral rates. We also applied the guidelines in routine surgeries to estimate the effect on rates of referral.

\section{Method}

The conclusions presented in this paper depend on the results of four independently collected sets of data: firstly, details of referrals from general practitioners to hospital collected from hospital computers; secondly, appropriateness of referrals as judged by the consultant who saw the patient; thirdly, appropriateness of referrals as judged by an independent general practitioner against a set of referral guidelines developed locally; and, fourthly, the effect of the referral guidelines on referral rates as judged by general practitioners who used the guidelines in their routine clinical practice.

The study was carried out in Cambridge Health Authority by using referral rates of general practitioners in the district and measuring doctors' perceptions of appropriateness of referrals to Addenbrooke's Hospital. This hospital is the only large hospital in Cambridge and is known from previous work to take most referrals from general practitioners in Cambridge. Patients seen in this hospital, however, include patients resident in other districts so the data on appropriateness includes some on patients referred from outside Cambridge district.

\section{MEASUREMENT OF REFERRAL RATES}

Data on rates of referral to hospital were collected from a regional database which had been established to collect data on patterns of outpatient referrals from hospital computers throughout East Anglia. Data had been collected from June 1990 for Cambridge Health Authority and the surrounding East Anglian districts. For the purpose of this study, data on referrals from May 1991 to April 1992 were used. Obstetric and psychiatric referrals were excluded.

Data from two additional sources were available to validate the data on the database-namely, information from the computers at the hospital that had been collected in 1989, and data from annual reports from general practice covering referrals between April 1990 and March 1991.

\section{SELECTION OF SAMPLE OF REFERRALS}

One hundred new referrals were selected from each of the following six specialties: chest medicine, orthopaedics, rheumatology, otorhinolaryngology, gynae- 
cology, and ophthalmology. Within specialties we identified several clinics for study and included all new patients seen by consultants in these clinics. The selection of individual clinics was determined largely by the availability of the research associate (AF). The data were collected over nine months during 1991. Of the 600 referrals selected for study in this way, 521 had been referred by general practitioners and 79 had been referred by other specialists.

\section{MEASUREMENT OF APPROPRIATENESS OF REFERRALS}

For each of the 600 referrals in the study the consultant completed a form which included the question: "Was this referral definitely appropriate or possibly/definitely inappropriate?" The specialists were not given specific guidance on the assessment of appropriateness. The research associate followed up referrals when the consultant did not complete the form during the clinic to ensure that all the forms were completed.

About half the referrals were for conditions covered in a set of referral guidelines developed during 1986 by Cambridge consultants and general practitioners from the Cambridge general practitioner trainer group, coordinated by one of the authors (HK). By using information in the referral letter, occasionally supplemented by information requested from the consultant, the reseach associate judged whether the referral seemed to follow the previously developed guidelines. Virtually all referral letters were typed.

ASSESSMENT OF EFFECT OF REFERRAL GUIDELINES ON GENERAL PRACTITIONERS' REFERRAL PATTERNS

Twenty one general practitioners were selected at random. Four declined to participate in the study, and others were selected in their place. General practitioner trainers were excluded as they might have taken part in the original development of the referral guidelines. Sixty of the guidelines were selected and divided into three clinical topics covering all the disciplines for which guidelines had been developed. Seven general practitioners were given guidelines relating to rheumatology, orthopaedics, and dermatology; seven were given guidelines relating to otorhinolaryngology, ophthalmology, and neurology; and seven were given those relating to paediatrics, chest medicine, and gynaecology. The general practitioners agreed to use the guidelines in their normal surgeries for two weeks. They completed a questionnaire for each patient who presented with a problem in one of the three clinical areas for which they had agreed to collect data. For each patient with a problem covered by one of the guidelines several questions were asked, including, for patients being referred to hospital, "If you had followed the referral protocol, would you still have referred the patient to hospital?" and for patients not being referred to hospital, "If you had followed the referral protocol, would you have referred this patient to hospital?" The purpose of these questions was to make a subjective estimate of the change in numbers of patients who would have been referred to hospital if the referral guidelines had been strictly followed.

TABLE II-Numbers and percentages of referrals judged possibly or definitely inappropriate by consultants

\begin{tabular}{|c|c|c|c|c|c|c|}
\hline \multirow[t]{2}{*}{ Specialty } & \multicolumn{2}{|c|}{$\begin{array}{c}\text { Referrals from } \\
\text { general practitioners }\end{array}$} & \multicolumn{2}{|c|}{$\begin{array}{c}\text { Referrals from } \\
\text { specialists }\end{array}$} & \multicolumn{2}{|c|}{ All referrals } \\
\hline & $\begin{array}{l}\text { No of } \\
\text { referrals }\end{array}$ & $\begin{array}{c}\text { No } \\
\text { inappropriate }\end{array}$ & $\begin{array}{l}\text { No of } \\
\text { referrals }\end{array}$ & $\begin{array}{c}\text { No } \\
\text { inappropriate }\end{array}$ & $\begin{array}{l}\text { No of } \\
\text { referrals }\end{array}$ & $\begin{array}{c}\text { No } \\
\text { inappropriate }\end{array}$ \\
\hline Rheumatology & 85 & 6 & 15 & 2 & 100 & 8 \\
\hline Orthopaedics & 85 & 31 & 15 & 2 & 100 & 33 \\
\hline Otorhinolaryngology & 90 & 1 & 10 & 2 & 100 & 3 \\
\hline Ophthalmology & 87 & 8 & 13 & 1 & 100 & 9 \\
\hline Chest medicine & 75 & 0 & 25 & 0 & 100 & 0 \\
\hline Gynaecology & 99 & 4 & 1 & 0 & 100 & 4 \\
\hline Total & 521 & $50(9 \cdot 6 \%)$ & 79 & $7(8.9 \%)$ & 600 & $57(9 \cdot 5 \%)$ \\
\hline
\end{tabular}

\section{Results}

VARIATION IN PRACTICE REFERRAL RATES

Data were collected for 31 practices. All practices referred more than three quarters of their patients to Addenbrooke's Hospital, and for the 31 practices together $95 \%$ of referrals were to this hospital. There was a $2 \cdot 5$-fold variation between practices in their rates of referral to hospital, from 84 to 208 referrals per 1000 patients per year (table I). When earlier data from the hospital computers were used the variation was also estimated at 2.5 fold; when data from annual reports from general practice were used, variation was estimated at fourfold. We were therefore confident in concluding that there was at least a $2 \cdot 5$-fold variation in referral rates between practices in the district.

APPROPRIATENESS OF REFERRALS

Of the 600 referrals selected for study, 521 were referred by general practitioners, the remainder being referred by hospital doctors. Table II shows the consultants' perception of the appropriateness of the 600 referrals studied. Similar judgments about appropriateness were made on referrals initiated by general practitioners and those initiated by specialists. Overall, the specialist judged the referral to be appropriate in 543 cases $(90.4 \%$ of referrals, $95 \%$ confidence interval $87 \cdot 1 \%$ to $93 \cdot 6 \%$ ). The percentage regarded as appropriate was over $90 \%$ of all specialties, with the exception of orthopaedics, in which only $67 \%$ of referrals were regarded as definitely appropriate.

Guidelines were available for 308 of the original sample of referrals from general practitioners. Table III shows the extent to which these were judged to follow the guidelines. Overall, the general practitioner was judged to have managed the case as suggested in the guidelines in 259 cases $(84 \cdot 1 \%$ of referrals, $80.0 \%$ to $88 \cdot 2 \%$ ).

TABLE III-Numbers and percentages of referrals judged not to conform to predetermined guidelines

\begin{tabular}{lcc}
\hline Specialty & No of referrals & $\begin{array}{c}\text { No judged not to conform } \\
\text { to management suggested } \\
\text { in referral guideline }\end{array}$ \\
\hline Rheumatology & 61 & 4 \\
Orthopaedics & 46 & 14 \\
Otorhinolaryngology & 74 & 4 \\
Ophthalmology & 56 & 14 \\
Chest medicine & 39 & 4 \\
Gynaecology & 32 & 9 \\
\hline Total & 308 & $49(15.9 \%)$ \\
\hline
\end{tabular}

CALCULATION OF MAXIMUM EFFECT OF INAPPROPRIATE REFERRALS ON VARIATION IN REFERRAL RATES

This section presents a theoretical calculation on the extent to which inappropriate referral could explain the variation in referral rates that exists between practices in the district. The data presented above suggest that between $10 \%$ and $15 \%$ of referrals could be regarded as possibly inappropriate by one of the two sets of criteria that were used. The question we considered is: "If $15 \%$ fewer patients were referred to hospital, by how much could this reduce the overall variation in referral rates?"

We would expect from previously published work that inappropriate referrals arise from practices with either high or low rates of referral. ${ }^{9}$ To estimate the maximum possible contribution of inappropriate referral to variation in rates of referral, however, we made the theoretical assumption that all inappropriate referrals arise in practices with high rates of referral. We then calculated the variation in referral rates which would remain if referrals from high referring practices were assumed to be reduced by the number of "possibly inappropriate" referrals.

We therefore took the data on referrals from 
practices shown in table I and made the assumption that the total number of referrals was to be reduced by $15 \%$ (5100 referrals over one year). We then took the practices with the top $25 \%$ of referral rates and calculated a reduction in their referral rates in proportion to their list sizes which would result in an overall reduction of 5100 patients referred. This calculation reduced the overall variation in practice referral rates from $2 \cdot 5$-fold (mean rate 145 referrals $/ 1000$ patients/ year, range $84-208$ ) to $2 \cdot 1$-fold (mean rate 123 referrals/ 1000 patients/year, range 84-174).

USE OF GUIDELINES IN GENERAL PRACTICES: POSSIBLE EFFECT ON RATES OF REFERRAL

General practitioners collected data on 5254 consultations. Of these, 662 consultations were for conditions in the clinical topics for which the general practitioners had been asked to collect data, and there was a referral guideline for 247 of these patients. Fifty three patients were already under the care of a hospital, and these were excluded from the study. Of the remaining 194 patients, 22 were referred to hospital. In these cases the general practitioners made a judgment in two cases that they would not have referred the patient to hospital had they followed the guideline strictly. In the remaining 172 cases which were not referred, the general practitioners judged that they would have referred the patient to hospital in six cases had the guidelines been followed strictly. The net effect of strict adherence to the guidelines would have been to increase the number of patients referred from 22 to 26 , an increase of $2 \cdot 1 \%$ in the percentage of consultations resulting in referral from $11.3 \%$ to $13.4 \%$ (95\% confidence interval of difference $-4.5 \%$ to $8.6 \%$; not significant).

\section{Discussion}

The three sources of data on referrals used in this study confirm what has been shown in many other locations-namely, that there is substantial variation between general practices in the rates of referral to hospital. Although each source of data may have included inaccuracies, for the purpose of the argument presented in this paper it is sufficient to establish that general practitioners in Cambridge vary in their referral patterns. In previous studies it has not been possible to explain more than a small proportion of the variation on the basis of characteristics of doctors, their patients, or their practices, ${ }^{12}$ and it has been suggested that doctors may have individual referral thresholds. ${ }^{10}$ Recent research suggests that the referral behaviour of doctors may be related to their particular clinical skills, ${ }^{11}$ willingness to take risks, ${ }^{12}$ response to pressure from patients, ${ }^{13}$ work satisfaction,,${ }^{14}$ and the context in which the referral decisions are made. ${ }^{15}$ Our purpose was to determine the extent to which variation in rates of referral could be explained on the basis of inappropriate referral as perceived by specialists or in relation

\section{Practice implications}

- There is a wide and unexplained variation in general practitioners' rates of referral

- This study investigated whether this variation is due to inappropriate referral according to specialists and to guidelines developed locally between general practitioners and specialists

- Elimination of all possibly inappropriate referrals reduced the variation in practice referral rates from $2 \cdot 5$-fold to $2 \cdot 1$-fold

- Unnecessary referral does not seem to explain the wide variation in rates of referral to hospital among general practitioners

- Referral guidelines could help to improve the quality of referrals but may not reduce the number of patients referred to guidelines derived by groups of doctors. We made no attempt to measure the patients' views on the referrals.

Overall, nearly $10 \%$ of referrals from general practitioners were rated as possibly or definitely inappropriate by the specialist who saw the patient. A higher proportion was rated inappropriate in orthopaedics, which is consistent with the results of another comparable study. ${ }^{4}$ About $16 \%$ of referrals were judged as possibly inappropriate by an independent general practitioner using a set of predetermined referral guidelines. In most cases in which the consultant rated a referral as possibly or definitely inappropriate the referral was also judged inappropriate by using the guidelines. Although we did not seek the views of referring general practitioners or patients in this study, previous work suggests that they would have judged a smaller proportion of referrals unnecessary than did specialists. We therefore regard $10 \%$ and $15 \%$ as a reasonable maximum estimate of the percentage of possibly inappropriate referrals in this sample. Indeed this estimate is much higher than the $4 \%$ of patients judged by specialists to have been referred unnecessarily or referred to the wrong clinic in a recent national survey by Cartwright and Windsor. ${ }^{16}$ Our calculations on the effect of these possibly inappropriate referrals on the variation in referral patterns show that in the theoretical setting in which all $15 \%$ of inappropriate referrals came from the practices with the highest $25 \%$ of referral rates, elimination of these referrals would have reduced the variation in referral rates only from $2 \cdot 5$-fold to $2 \cdot 1$-fold, leaving the greater part of the variation unexplained. We therefore conclude that within this authority a relatively small proportion of the variation in rates of referral by general practitioners can be explained by inappropriate referrals.

When patients who may have been inappropriately referred to hospital are taken into account, however, it is important to consider those who may inappropriately have not been referred-that is, those who were not referred to hospital even though they could have benefited from referral. ${ }^{17}$ We estimated the effect of guidelines on referral patterns on the basis of the subjective judgment of general practitioners by using the guidelines in the course of routine consultations. These data suggest that strict application of the referral guidelines would have been unlikely to change rates of referral significantly.

None of our results argues against careful review of the quality of care provided by general practitioners or against the value of using management guidelines as an aid to clinical decision making. Indeed we believe that the development of such guidelines can be valuable, as shown in a recent study on the use of infertility guidelines by general practitioners in the Grampian region. ${ }^{18}$ Our results, however, suggest that concentrating on inappropriate referrals may be an ineffective way of trying to understand variation in referral patterns. We are aware of health authorities who have sought to introduce referral guidelines with the explicit intent to reduce numbers of patients referred. Our results suggest that unthinking attempts to impose referral guidelines are unlikely to reduce the numbers of patients referred to hospital.

This study was supported with a grant from East Anglian Regional Health Authority. We thank the consultants and general practitioners in Cambridge who collaborated with this project.

1 Wilkin D. Patterns of referral: explaining variation. In: Roland MO, Coulter A, eds. Hospital referrals. Oxford: Oxford University Press, 1992:76-91.

2 Roland MO. Variations in referral rates of general practitioners: causes and significance. In: Hopkins A, Wallace P, eds. Referrals to medical outpatients. London: Royal College of Physicians and Royal College of General Practitioners, 1992:33-42.

3 Grace JF, Armstrong D. Referrals to hospital: perceptions of patients, genera 
practitioners and consultants about necessity and suitability of referral. Family Practice 1987;14:170-5.

4 Roland MO, Porter R, Matthews JG, Redden JF, Simonds GW, Bewley B. Improving care: a study of orthopaedic outpatient referrals. BMf 1991;302 $1124-8$.

5 Roland MO. Measuring appropriateness of hospital referrals. In: Roland MO Coulter A, eds. Hospital referrals. Oxford: Oxford University Press, 1992: Coulter A.

6 Haines A, Armstrong D. Developing referral guidelines. In: Roland MO, Coulter A, eds. Hospital referrals. Oxford: Oxford University Press, 1992:163-78.

7 Emmanuel J, Walker N. Referrals from general practice to hospital outpatient departments: a strategy for improvement. $B M \tilde{f} 1989 ; 299: 722-4$.

8 Coulter A. The patient's perspective. In: Roland MO, Coulter A, eds. Hospital referrals. Oxford: Oxford University Press, 1992:123-35.

9 Knottnerus JA, Joosten J, Daams J. Comparing the quality of referrals of general practitioners with high and average referral rates: an independen panel review. Brf Gen Pract 1990;40:178-81.

10 Cummins RO, Jarman B, White PM. Do general practitioners have different "referral thresholds"? BMF 1981;282:1037-9.

11 Reynolds GA, Chitnis JG, Roland MO. General practitioner outpatien referrals: do good doctors refer more patients to hospital? BMf 1991;302: 1250-1.

12 Grol R, Whitfield M, De Maeseneer J, Mokkink H. Attitudes to risk taking in medical decision making among British; Dutch and Belgian general medical decision making among British;

13 Armstrong D, Fry J, Armstrong P. Doctors' perceptions of pressure from patients for referral. $B M 71991 ; 302: 1186-8$.

14 Grol R, Mokkink H, Smits A, Van Eijk J, Beek M, Mesker P, et al. Work satisfaction of general practitioners and quality of patient care. Fam Pract 1985;2:128-35

15 Newton J, Hayes V, Hutchinson A. Factors influencing general practitioners' referral decisions. Fam Pract 1991;8:308-13.

16 Cartwright A, Windsor J. Outpatients and their doctors. London: Department of Health, Institute for Social Studies in Medical Care, 1992

17 Roland MO, Green C, Roberts SOB. Should general practitioners refer more patients to hospital? $\mathcal{F} R$ Soc Med 1991;84:403-4.
18 Emslie C, Grimshaw J, Templeton A. Do clinical guidelines improve general practice management and referral of infertile couples? $B M F$ 1993;306: 1728-30.

(Accepted 28 September 1993)

\section{Correction}

General practice fundholding: observations on prescribing patterns and costs using the defined daily dose method

An editorial error occurred in this paper by $M$ Maxwell and colleagues (6 November, pp 1190-4). The third table in appendix 1 should not have included the column showing the total defined daily doses (ddds) for all prescriptions. The correct table is shown below.

\begin{tabular}{llc}
\hline Drug prescribed & Quantity $\times$ dose + ddd & No of ddds \\
\hline Cimetidine $200 \mathrm{mg}$ & $(240 \times 200=48000) / 800$ & 60 \\
Cimetidine $400 \mathrm{mg}$ & $(600 \times 400=240000) / 800$ & 300 \\
Ranitidine $150 \mathrm{mg}$ & $(280 \times 150=42000) / 300$ & 140 \\
Ranitidine $300 \mathrm{mg}$ & $(180 \times 300=54000) / 300$ & 180 \\
Omeprazole $20 \mathrm{mg}$ & $(540 \times 20=10800) / 20$ & 540 \\
\hline & & 1220 \\
\hline
\end{tabular}

Drugs prescribed: 360 ddds of cimetidine, 320 ddds of ranitidine, 540 ddds of omeprazole.

Total $=1220$ ddds of ulcer healing drugs.

\section{UNDERSTANDING EPIDEMIOLOGY}

\section{Measures of disease frequency}

For epidemiological purposes the occurrence of cases of disease must be related to the "population at risk" giving rise to the cases. Several measures of disease frequency are in common use.

\section{Incidence}

The incidence of a disease is the rate at which new cases occur in a population during a specified period. For example, the incidence of thyrotoxicosis during 1982 was $10 / 100000 /$ year in Barrow-in-Furness compared with 49/100 000/year in Chester.

When the population at risk is roughly constant, incidence is measured as:

\section{Number of new cases}

Population at risk $\times$ time during which cases were ascertained

Sometimes measurement of incidence is complicated by changes in the population at risk during the period when cases are ascertained, for example, through births, deaths, or migrations. This difficulty is overcome by relating the numbers of new cases to the person years at risk, calculated by adding together the periods during which each individual member of the population is at risk during the measurement period. Thus incidence is defined as:

\section{$\frac{\text { Number of new cases }}{\text { Total person years at risk }}$}

It should be noted that once a person is classified as a case, he or she is no longer liable to become a new case, and therefore should not contribute further person years at risk. Sometimes the same pathological event happen more than once to the same individual. In the course of a study, a patient may have several episodes of myocardial infarction. In these circumstances the definition of incidence is usually restricted to the first event, although sometimes (for example, in the study of infectious diseases) it is more appropriate to count all episodes. When ambiguity is possible reports should state whether incidence refers only to first diagnosis or to all episodes, as this may influence interpretation. For example, gonorrhoea notification rates in England and Wales have increased dramatically, but no one knows to what extent this is due to more people getting infected or to the same people getting infected more often.

\section{Prevalence}

The prevalence of a disease is the proportion of a

population that are cases at a point in time. The prevalence of persistent phlegm production in middle aged men in Britain has been estimated at about $10 \%$, the condition being defined by a response to a standard questionnaire. Prevalence is an appropriate measure only in such relatively stable conditions, and it is unsuitable for acute disorders.

Even in a chronic disease, the manifestations are often intermittent. In consequence, a "point" prevalence, based on a single examination, at one point in time, tends to underestimate the condition's total frequency. If repeated or continuous assessments of the same individuals are possible, a better measure is the period prevalence defined as the proportion of a population that are cases at any time within a stated period. Thus, the 12 month period prevalence of low back pain in a sample of British women aged $30-39$ was found to be $33 \cdot 6 \%$.

\section{Mortality}

Mortality is the incidence of death from a disease.

\section{Interrelation of incidence, prevalence, and mortality}

Each new (incident) case enters a prevalence pool and remains there until either recovery or death:

$$
\text { Incidence } \rightarrow \text { prevalence }\left\{\begin{array}{l}
\rightarrow \text { recovery } \\
\rightarrow \text { death }
\end{array}\right.
$$

If recovery and death rates are low, then chronicity is high and even a low incidence will produce a high prevalence:

$$
\text { Prevalence }=\text { incidence } x \text { average duration }
$$

In studies of aetiology, incidence is the most appropriate measure of disease frequency. Mortality is a satisfactory proxy for incidence if survival is not related to the risk factors under investigation. However, patterns of mortality can be misleading if survival is variable. A recent decline in mortality from testicular cancer is attributable to improved cure rates from better treatment, and does not reflect a fall in incidence.

Prevalence is often used as an alternative to incidence in the study of rare chronic diseases such as multiple sclerosis, where it would be difficult to accumulate large numbers of incident cases. Again, however, care is needed in interpretation. Differences in prevalence between different parts of the world may result from differences in survival and recovery as well as in incidence.

From Geoffrey Rose, D J P Barker, D Coggon. Epidemiology for the Uninitiated, 3rd edition, 1993. Available from the BMJ Bookshop, price $£ 6.95$ 